\title{
The women made it work: fuzzy transitive closure of the results chain in a dengue prevention trial in Mexico
}

\author{
Neil Andersson ${ }^{1,2^{*}}$, Mario Beauchamp ${ }^{3}$, Elizabeth Nava-Aguilera' ${ }^{1}$, Sergio Paredes-Solís ${ }^{1}$ and Mateja Šajna ${ }^{4}$ \\ From The Camino Verde Trial colloquium \\ Acapulco, Mexico. 17-21 June 2013
}

\begin{abstract}
Background: A modified theory of planned behaviour (acronym CASCADA) proposes that Conscious knowledge precedes a change in Attitude, which in turn precedes positive deviations from negative Subjective norms, intention to Change, perception of Agency to change, Discussion of possible action, and Action itself. We used this as a results chain to investigate gender-specific behaviour dynamics in chemical-free dengue prevention.

Methods: Secondary analysis of the Mexican arm of a cluster randomised controlled trial used household survey data on intermediate outcomes of dengue prevention behaviour. We used a matrix of odds ratios between outcomes, transformed to a symmetrical range $(-1,1)$, to compute fuzzy transitive closure of the results chain for control and intervention clusters, then for male and female respondents separately in each group. Transitive closure of a map computes the influence of each factor on each other factor, taking account of all influences in the system. Cumulative net influence was the sum of influences across the results chain.

Results: Responses of 5042 women and 1143 men in 45 intervention clusters contrasted with those of 5025 women and 1179 men in 45 control clusters. Control clusters showed a distal block (negative influence) in the results chain with a cumulative net influence of 0.88 ; intervention clusters showed no such block and a cumulative net influence of 1.92. Female control respondents, like the overall control picture, showed a distal block, whereas female intervention responses showed no such blocks (cumulative net influence 0.78 and 1.73 respectively). Male control respondents showed weak distal blocks. Male intervention responses showed several new negative influences and a reduction of cumulative net influence (1.38 in control and 1.11 in intervention clusters).

Conclusions: The overall influence of the intervention across the results chain fits with the trial findings, but is different for women and men. Among women, the intervention overcame blocks and increased the cumulative net influence of knowledge on action. Among men, the intervention did not reinforce prevention behaviour. This might be related to emphasis, during the intervention, on women's participation and empowerment. The fuzzy transitive closure of the CASCADA map usefully highlights the differences between gender-specific results chains.
\end{abstract}

Trial registration: ISRCTN27581154.

Keywords: Dengue, Community mobilisation, Behaviour change model, Fuzzy transitive closure

\footnotetext{
* Correspondence: andersson@ciet.org

${ }^{1}$ Centro de Investigación de Enfermedades Tropicales (CIET), Universidad

Autónoma de Guerrero, Acapulco, Guerrero, Mexico

${ }^{2}$ Department of Family Medicine, McGill University, Montreal, Canada

Full list of author information is available at the end of the article
}

(c) The Author(s). 2017 Open Access This article is distributed under the terms of the Creative Commons Attribution 4.0 International License (http://creativecommons.org/licenses/by/4.0/), which permits unrestricted use, distribution, and reproduction in any medium, provided you give appropriate credit to the original author(s) and the source, provide a link to the Creative Commons license, and indicate if changes were made. The Creative Commons Public Domain Dedication waiver (http://creativecommons.org/publicdomain/zero/1.0/) applies to the data made available in this article, unless otherwise stated. 


\section{Background}

A recent cluster randomised controlled trial in Mexico and Nicaragua showed a convincing impact of evidencebased community mobilisation on risk of dengue [1]. The Camino Verde intervention had a positive effect on all outcome parameters (serological evidence of dengue virus infection in children, self-reported dengue cases and all conventional vector indices). Earlier trials of community-based interventions have shown impact on entomological indices [2-9], but the Camino Verde trial was the first to show impact on dengue virus infection. It is likely that there will be increased emphasis on community-mobilisation for prevention of dengue and other diseases borne by the Aedes aegypti vector, especially with evidence from the Camino Verde trial and from other studies [10-13] of the lack of effectiveness of the use of the organophosphate pesticide temephos in household water stores in reducing vector indices and dengue infection [14].

While the Camino Verde intervention had impact, it did not eradicate the vector or dengue virus infection in the intervention clusters. It is important to know how interventions of informed community mobilisation for dengue prevention achieve an impact and how they might be fine-tuned to increase their impact. Complex interventions can change many aspects of human behaviour. In the impact study of the Camino Verde trial, we measured a number of intermediate behavioural outcomes. These are described in the CASCADA model, based on the theory of planned behaviour $[15,16]$. This extends the knowledge, attitudes and practices (KAP) model of behaviour change popularised in the 1960s [17].

Recognising the well-documented limitations of the KAP model $[18,19]$, our acronym CASCADA $[20,21]$ describes a partial order of intermediate outcomes through Conscious knowledge, Attitudes, Subjective norms and positive deviation from these, intention to Change, Agency (individual and collective) to make change, Discussion of possible action and, finally, Action or change of practice. We used the CASCADA model as the basis of a randomised trial of an intervention to increase vaccination uptake in Pakistan [22, 23] and in analysis of a crosssectional study in southern Africa [24]. A qualitative analysis of narratives of young women in three southern African countries validated the CASCADA model in the case of action to prevent gender violence [25].

Our CASCADA model uses the constructs of the conventional theory of planned behaviour. Figure 1 shows the differences between CASCADA and the conventional theory of planned behaviour [15]. First, we propose CASCADA as a partial order, not an invariable or linear sequence, but different to the parallel constructs seen in the conventional theory: knowledge generally precedes attitude; attitude shifts generally precede a positive deviation from a negative subjective norm; and so on. Second, the CASCADA model adds "Discussion/Socialisation" as a measurable construct between Agency (perceived behaviour control) and Action (behaviour). We base this on the observation that where behaviour change is an essentially SOCIAL outcome, it is reasonable to expect discussion or socialisation one step before implementation.

The Camino Verde trial reported unremarkable differences in CASCADA outcomes between intervention and control clusters: there was a significant difference in only one intermediate outcome, Agency or collective selfefficacy (RRR 9.6\% 95\%CI 3.4-15.8) [1].

Here we report a secondary analysis of the impact of the Camino Verde intervention on the outcomes in the CASCADA results chain in all respondents and in men and women separately, in the Mexican arm of the trial, as part of our efforts to understand the genderspecific individual responses to the community-led intervention.

\section{Methods}

The methods and results of the Camino Verde trial are described in detail elsewhere [1]. This secondary analysis used data from the impact survey of the trial in Mexico in 2013. Fieldworkers interviewed household respondents in 45 intervention and 45 control clusters in the coastal region of Guerrero state. The Camino Verde CASCADA model included the following variables: Conscious knowledge $(C)$ was the ability to identify a physical sample of a mosquito larva (the interviewer showed a physical larva and took mention of "mosquito" in the response to indicate conscious knowledge of the mosquito life cycle). Attitude (At) to vector control was the response to the question: Do you consider it worthwhile (vale la pena) to spend time and money every week to eliminate mosquito breeding sites (criaderos) in your house. Subjective norm (S) was derived from the question: Do you think your neighbours consider it worthwhile to spend time .... Intention to Change (iC) used the question: Do you plan to spend time and money each week to eliminate mosquito breeding sites in your house. Agency (Ag) derived from answers like "myself" or "ourselves" to the question: Who is responsible for control of mosquito breeding sites. Discussion (D) about prevention derived from the response to the question: How often do you chat with your neighbours about how to control mosquitos. These two constructs, Agency and Discussion, replace perceived behaviour control in a more usual theory of planned behaviour [26]: Agency refers to both self-efficacy and collective efficacy; we included Discussion as a linkage to factors that facilitate the performance of the behaviour. Action (A) focused on participation in collective activities in the neighbourhood to control mosquito breeding sites. 


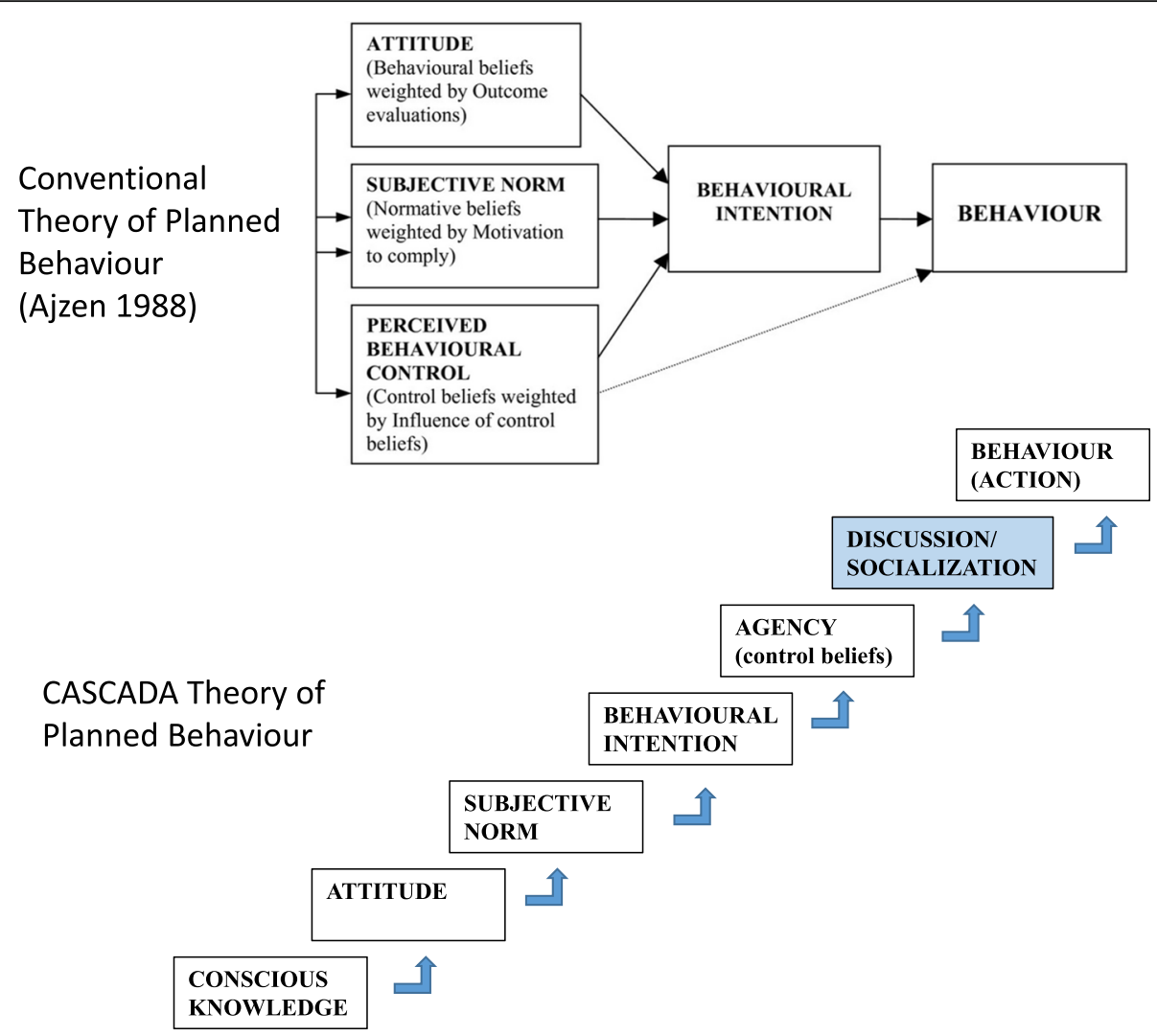

Fig. 1 The CASCADA results chain compared with the conventional theory of planned behaviour

\section{Analysis}

The analysis involved computation of fuzzy transitive closure technique of each CASCADA results chain. We used the command TABMAT in CIETmap [27] - open source software with an interface in the statistical programming language $\mathrm{R}$ - to generate a matrix of unadjusted odds ratios between each pair of variables in the CASCADA partial order. Using the formula

$$
1-(2 /(\mathrm{OR}+1))
$$

we converted the odds ratios to the interval $[-1,1]$ and inputted the resulting matrix to FuzzyTC [28], a software package that computes the fuzzy transitive closure of a cognitive map [29].

Transitive closure has been used for analysis of cognitive maps in public health [30] and medicine [31]. Probabilistic transitive closure is applicable to fuzzy cognitive maps where the weights for the arcs can be interpreted as probabilities of the corresponding causal relations [28, 29]. For the CASCADA results chain, however, the fuzzy transitive closure model is more suitable [28].

This model assumes that the weight $w(A ; B)$ of the arc $(A ; B)$ is the strength of the direct influence of factor $A$ on factor $B$. It is positive if an increase in $A$ results in an increase in $B$ or if a decrease in $A$ results in a decrease in $B$. It is negative if an increase in $A$ results in a decrease in $B$, or decrease in $A$ results in an increase of $\mathrm{B}$. For transitive closure to be meaningful, these influences must be direct and not involve any other factors under consideration. Also, the weights must be in the interval $[-1,1]$, which is fulfilled after the transformation of the odds ratios into this range.

An $\operatorname{arc}(A ; B)$ in the transitive closure arises either from a direct influence $(\operatorname{arc})(\mathrm{A} ; \mathrm{B})$ in the CASCADA map, or else from a walk (sequence of arcs) of direct influences starting at $\mathrm{A}$ and ending at $\mathrm{B}$. The weight of the $\operatorname{arc}(\mathrm{A} ; \mathrm{B})$ in the fuzzy transitive closure is the maximum weight of any of the walks from $A$ to $B$, and the weight of a walk is the minimum of the weights of any of its arcs. Thus, the arcs of the CASCADA map can be seen as links in a chain. An arc in the fuzzy transitive closure is considered as strong as the bundle of chains that links its ends, and the strength of a chain is measured by the strength of its weakest link.

The resulting weight of the $\operatorname{arc}(\mathrm{A} ; \mathrm{B})$ in the transitive closure is interpreted as the overall (positive or negative) influence of factor $\mathrm{A}$ on factor $\mathrm{B}$, which takes into account all direct influences in the original map.

FuzzyTC returns the fuzzy transitive closure in the form of two matrices, one of positive and the other of 
negative-weight arcs. We added these two matrices to obtain the net fuzzy transitive closure. Finally, we calculated the cumulative net influence (in the range -6 to 6 ) as the sum of the weights of the influences in the fuzzy transitive closure over all arcs of the original CASCADA chain.

\section{Results}

We analysed responses of 6185 people (5042 women and 1143 men) in the intervention group and 6204 (5025 women and 1179 men) in the control group. The left side of Fig. 2 shows the net transitive closure of the CASCADA map derived from responses in the 45 control communities. Green arcs represent the positive net influences and red arcs the negative net influences, all in the direction of Action. Thicker lines indicate stronger influences. Conscious knowledge has an influence on Attitude, Subjective norm, and each subsequent step in the CASCADA. Attitude influences Subjective norm, Change intention, and each subsequent step in the CASCADA. In the control clusters, there is a negative influence of intention to Change on Discussion and on Action; also of Agency on Discussion; and of Agency on Action. The cumulative net influence across the CASCADA sequence is 0.88 out of a possible maximum value of 6 (which would be attained if every outcome in the CASCADA results chain had the strongest possible positive influence on the next factor in the chain).

The right side of Fig. 2 shows the analysis of the net transitive closure of the CASCADA map of outcomes in the 45 intervention clusters. The negative influences in the control clusters - red arrows between intention to Change, Agency and Action - do not appear in the intervention responses; instead there are strongly positive influences in the intervention group. The net influence of these variables on Action is consequently much higher in the intervention than in the control clusters (1.92 versus 0.88 ). The only negative arc is between Conscious knowledge and Subjective norms, the implication being that the more people in intervention sites knew about dengue prevention, the less they recognised incompatible norms of their neighbours.

Among female respondents (Fig. 3), the control group showed much the same picture as did the overall control group. The intervention group, again like the overall picture, showed positive arcs replacing the negative arcs from Agency to Discussion and from Agency to Action. Two negative arcs emerged: between Attitudes to prevention and Agency, and Subjective norms to Agency. The cumulative net influence increased from 0.78 to 1.73 with the intervention.

Figure 4 shows the findings for male respondents. Male control responses showed similar patterns to female control responses but male intervention responses were very different to female intervention responses. Four strongly negative arcs emerged among men in intervention clusters, with Conscious knowledge negatively related to Subjective norms, intention to Change, Discussion and Action. Among male respondents, the cumulative net influence decreased from 1.38 in the control clusters to 1.11 in the intervention clusters.

\section{Discussion and conclusions}

Fuzzy transitive closure allowed scrutiny of the proposed results chain underlying dengue prevention action in the Camino Verde trial. The cumulative net influence across the CASCADA partial order of intermediate outcomes is compatible with the main finding of the trial, illustrating a likely mechanism of the positive influence on participant behaviour. Positive arcs between Change intention or Agency and Discussion or Action replaced negative arcs in the control clusters, probably related to the

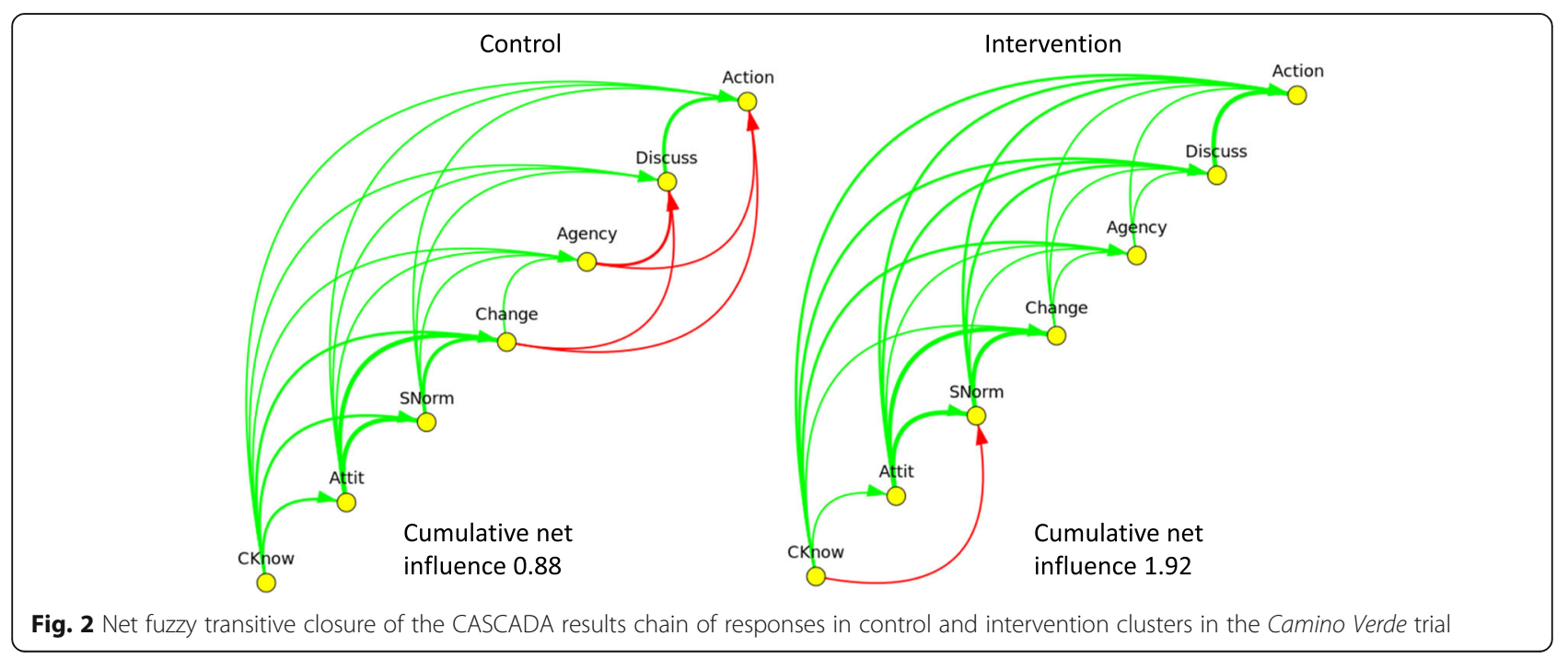




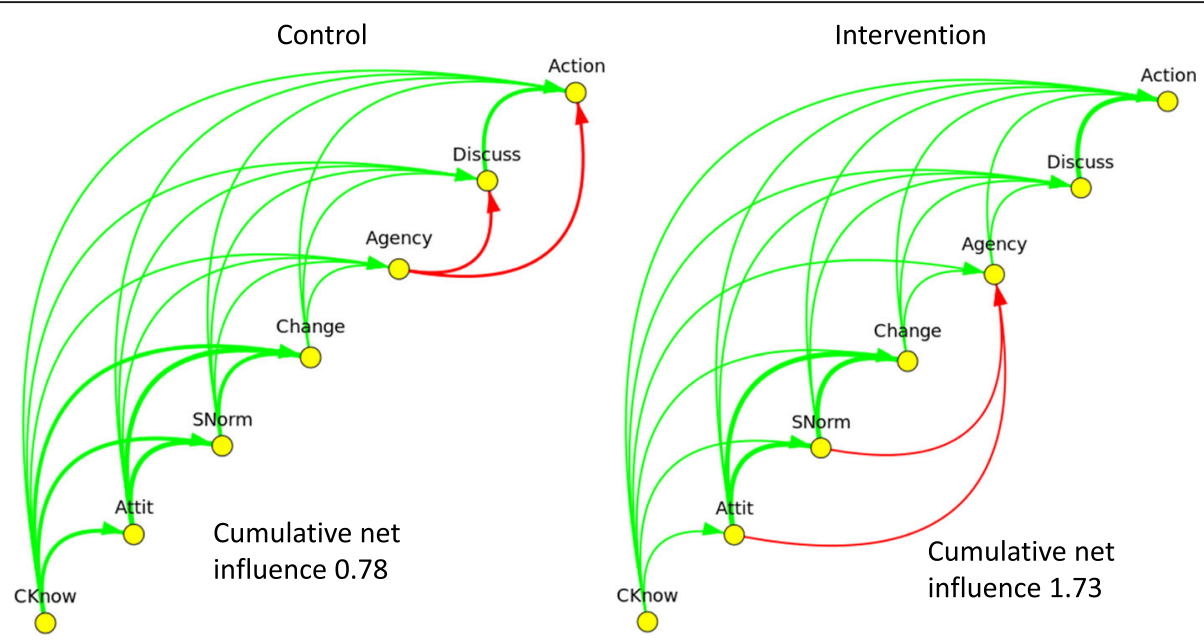

Fig. 3 Net fuzzy transitive closure of the CASCADA results chain of female responses in control and intervention clusters in the Camino Verde trial

multiple opportunities to discuss prevention offered by the intervention, and reflected in the increase in collective efficacy (Agency) reported in the original study [1].

The transitive closure of the CASCADA model emerging from male and female responses, however, is quite different. Among women, the intervention appears to have overcome blocks in the distal partial order and increased the net influence of Conscious knowledge on Action. It seems plausible that this accounts for most of the measured impact in the trial.

Responses from men suggest the Camino Verde intervention did not work well for them, in the important sense that it did not generate or reinforce positive prevention behaviour in this group. If anything, the intervention seems to have weakened the existing influence of knowledge on action shown in the control group, quite possibly demotivating men.
It is possible that the male responses included in our analysis represent a selected and minority view - there were many fewer male than female household respondents, and the male responses came from men who were at home at the time of the survey, when most men were out at work. The findings may also be related to the intentional emphasis of the intervention on women's participation and empowerment. The Camino Verde intervention was gendered in the sense that it engaged, mobilised and empowered women. The negative reaction of men might have represented some sort of pushback in the context of women engaging in community issues that might ordinarily have been a male domain. This phenomenon is well recognised in other spheres of development involving women's empowerment [32-34]. In a broader and probably more correct sense of gendering interventions, we should also have considered and
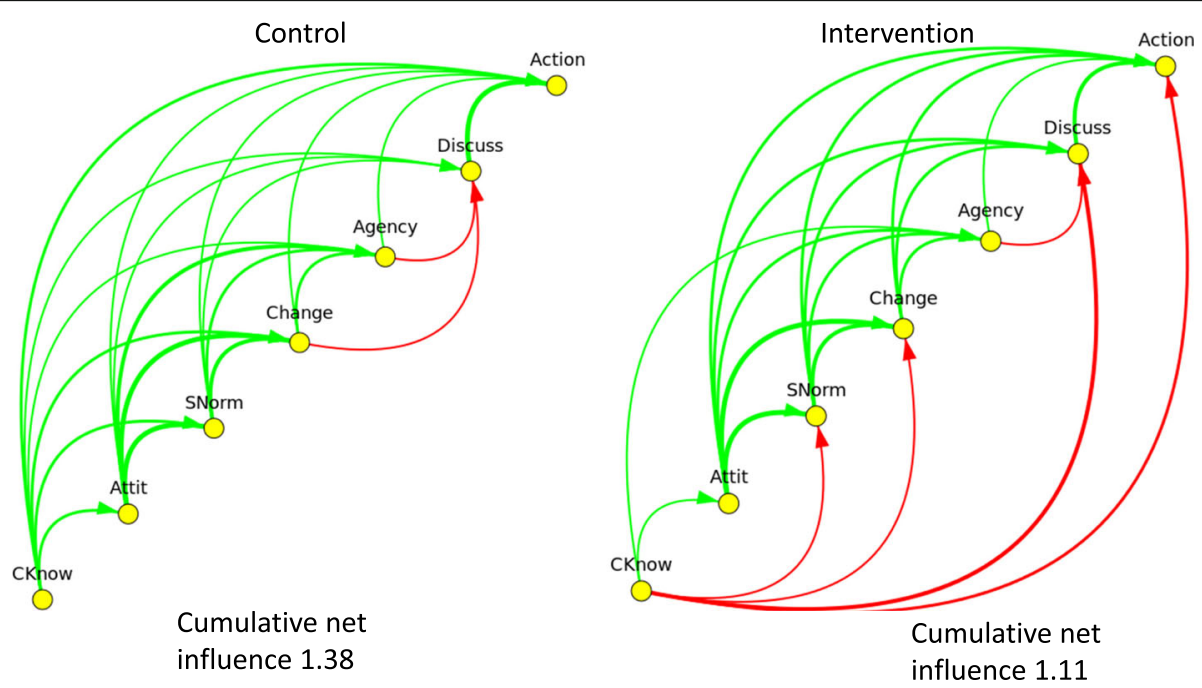

Fig. 4 Net fuzzy transitive closure of the CASCADA results chain of male responses in control and intervention clusters in the Camino Verde trial 
addressed the potential effect of women's engagement on their spouses.

Fuzzy transitive closure operationalises the CASCADA partial order by quantifying the sequential relationship (for example, Knowledge leading to Attitudes) in the context of all other relationships between Knowledge and Attitudes, in both directions. The resulting quantification is context and subgroup specific, as the relative influence of the network of different constructs will change with context. Fuzzy transitive closure incorporates the influences of all other arcs, to generate the summary that is very different for men and women even in the same communities. The difference is informative, fuelling discussions about intervention gender dynamics.

As far as we can ascertain, this is the first use of transitive closure to analyse gender specific results chains in behaviour change interventions. By treating the intermediate outcomes as a network with each node potentially related to every other node, transitive closure provides a coherent summary of the overall relation between knowledge and preventive action. It allows us to evaluate the results chain in a way that appropriately emphasises the weakest link in the chain. It also illustrates in a compelling way where "blocks" in the CASCADA need to be confronted and, in the counterfactual comparison allowed by the Camino Verde trial, whether the intervention overcomes these blocks.

Our conclusion is that future dengue prevention interventions have to work effectively with both women and men, perhaps beginning with gender-stratified action planning and then bringing together the two groups for strategic discussions about who tackles what part of the problem.

\section{Funding}

The UBS Optimus Foundation provided funding for the trial in both Nicaragua and Mexico. Fomix-CONACYT-GUERRERO supported the work in Acapulco (Grant Number 2008-02-108,541). UBS Optimus Foundation provided the funding for this publication.

\section{Availability of data and materials}

No additional data available.

\begin{abstract}
Authors' contributions
NA was principal investigator in the Mexican trial, wrote the proposals, contributed to design and coordination, did the principal analysis and prepared this article; ENA was lead researcher in Mexico and contributed to the design and drafting; SP contributed to the fieldwork, analysis and drafting. MB contributed to drafting this article and designed the figures used; MŠ developed the mathematical basis for fuzzy transitive closure, wrote the FuzzyTC programme and contributed to the design and drafting of this paper. All authors read and approved the final manuscript
\end{abstract}

\section{Competing interests}

The authors declare that they have no competing interests.

\section{Ethics approval and consent to participate}

The study protocol was approved by the Research Ethics Board of CIETcanada on 16 November 2009 and the Ethics Committee of the Centro de Investigación de Enfermedades Tropicales (CIET) at the Autonomous University of Guerrero on 27 November 2009. Local authorities and community leaders gave their consent for the study and household respondents gave informed consent to participate.

\section{About this supplement}

This article has been published as part of BMC Public Health Volume 17 Supplement 1, 2017: The Green Way to Aedes aegypti mosquito control: aspects and implications of the Camino Verde trial in Mexico and Nicaragua. The full contents of the supplement are available online at https:// bmcpublichealth.biomedcentral.com/articles/supplements/volume-17supplement-1.

\section{Author details}

${ }^{1}$ Centro de Investigación de Enfermedades Tropicales (CIET), Universidad Autónoma de Guerrero, Acapulco, Guerrero, Mexico. ${ }^{2}$ Department of Family Medicine, McGill University, Montreal, Canada. ${ }^{3}$ CIETcanada, 160 George Street, Ottawa, Canada. ${ }^{4}$ Department of Mathematics and Statistics, University of Ottawa, Ottawa, Canada.

Published: 30 May 2017

\section{References}

1. Andersson N, Nava-Aguilera E, Arosteguí J, Morales-Perez A, Suazo-Laguna $\mathrm{H}$, Legorreta-Soberanis J, et al. Evidence based community mobilization for dengue prevention in Nicaragua and Mexico (Camino Verde, the green way): cluster randomized controlled trial. BMJ. 2015;351:h3267.

2. Heintze C, Velasco Garrido M, Kroeger A. What do community-based dengue control programmes achieve? A systematic review of published evaluations. Trans R Soc Trop Med Hyg. 2007;101:317-25.

3. Vanlerberghe V, Toledo ME, Rodríguez M, Fomez D, Baly A, Benitez JR, et al. Community involvement in dengue vector control: cluster randomised trial. BMJ. 2009:338:1959.

4. Arunachalam N, Tyagi BK, Samuel M, Krishnamoorthi R, Manavalan R, Tewari SC, et al. Community-based control of Aedes aegypti by adoption of eco-health methods in Chennai City, India. Pathog Glob Health. 2012;106:488-96.

5. Kittayapong $\mathrm{P}$, Thongyuan S, Olanratmanee $\mathrm{P}$, Aumchareoun W, Koyadun S, Kittayapong $\mathrm{R}$, et al. Application of eco-friendly tools and eco-bio-social strategies to control dengue vectors in urban and peri-urban settings in Thailand. Pathog Glob Health. 2012;106:446-54.

6. Espinoza-Gomez F, Hernandez-Suarez CM, Coll-Cardenas R. Educational campaign versus malathion spraying for the control of Aedes aegypti in Colima, Mexico. J Epidemiol Community Health. 2002;56:148-52.

7. Lloyd LS, Winch P, Ortega-Canto J, Kendall C. Results of a community-based Aedes aegypti control programme in Merida, Yucatan, Mexico. Am J Trop Med Hyg. 1992;46:635-42.

8. Leontsini E, Gil E, Kendall C, Clark GG. Effect of a community-based Aedes aegypti control programme on mosquito larval production sites in El Progreso, Honduras. Trans R Soc Trop Med Hyg. 1993;87:267-71.

9. Castro M, Sanchez L, Perez D, Carbonell N, Lefevre P, Vanlerberghe V, et al. A community empowerment strategy embedded in a routine dengue vector control programme: a cluster randomised controlled trial. Trans $\mathrm{R}$ Soc Trop Med Hyg. 2012;106:315-21.

10. Braga IA, Lima JBP, da Silva SS, Valle D. Aedes aegypti Resistance to temephos during 2001 in several municipalities in the states of Rio de Janeiro, Sergipe, and Alagoas, Brazil. Mem Inst Oswaldo Cruz. 2004;99:199-203.

11. Jirakanjanakit B, Saengtharatip S, Rongnoparut P, Duchon S, Bellec C, Yoksan $\mathrm{S}$. Trend of temephos resistance in Aedes aegypti mosquitoes in Thailand during 2003-2005. Environ Entomol. 2007;36:506-11.

12. Lima JBP, da Cunha MP, da Silva Junior RC, Galardo AKR, da Silva SS, Braga IA, et al. Resistance of Aedes aegypti to organophosphates in several municipalities in the state of Rio de Janeiro and Espirito Santo, Brazil. Am J Trop Med Hyg. 2003;68:329-33.

13. Rodriguez MM, Bisset JA. Fernandez D. Levels of insecticide resistance and resistance mechanisms in Aedes aegypti from some Latin american countries. J Am Mosq Control Assoc 2007;23:420-429.

14. Arosteguí J, Coloma J, Hernández-Alvarez C, Suazo-Laguna H, Balmaseda A,

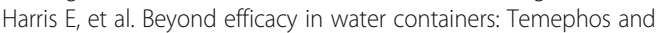
household entomological indices in six studies between 2005 and 2013 in 
Managua. Nicaragua, BMC Public Health. 2017;17(Suppl 1): doi:10.1186/ s12889-017-4296-6.

15. Ajzen I. The theory of planned behavior. Organ Behav Hum Decis Process. 1991:50:179-211. doi:10.1016/0749-5978(91)90020-T.

16. Albarracin D, Johnson BT, Fishbein M, Muellerleile PA. Theories of reasoned action and planned behavior as models of condom use: a meta-analysis. Psychol Bull. 2001;127:142-61.

17. Chilman C. Fertility and poverty in the United States: some implications for family planning programs, evaluation and research. J Marriage Fam. 1968;30:207-27.

18. Bentler PM, Speckart G. Models of attitude-behavior relations. Psychol Rev. 1979;86:452-64.

19. Baranowski T, Cullen KW, Nicklas T, Thompson D, Baranowski J. Are current health behavioural change models helpful in guiding prevention of weight gain efforts? Obes Res. 2003;11:23S.

20. Andersson N, Ledogar RJ. The CIET aboriginal youth resilience studies: 14 years of capacity building and methods development in Canada. Pimatisiwin. 2008:6:65-88.

21. Andersson N. Building the community voice into planning: 25 years of methods development in social audit. BMC Health Serv Res. 2011;11:S1.

22. Andersson N, Cockcroft A, Ansari N, Omer K, Losos J, Ledogar RJ et al. Household cost-benefit equations and sustainable universal childhood immunisation: a randomised cluster controlled trial in south Pakistan [ISRCTN12421731] BMC Public Health. 2005;5:72.

23. Andersson N, Cockcroft A, Ansari NM, Omer K, Baloch M, Ho Foster A, et al. Evidence-based discussion increases childhood vaccination: a randomised cluster controlled trial of knowledge translation in Pakistan. BMC Int Health Hum Rights. 2009;9:S8.

24. Mitchell S, Cockcroft A, Lamothe G, Andersson N. Equity in HIV testing: evidence from a cross-sectional study in ten southern African countries. BMC Int Health Hum Rights. 2010;10:23.

25. Cameron M, Cockcroft A, Wanjiru-Waichigo G, Marokoane N, Laetsang D, Andersson N. From knowledge to action: participant stories of a population health intervention to reduce gender violence and HIV in three southern African countries. AIDS Care. 2014;26:1534-40.

26. Noar SM, Zimmerman RS. Health behavior theory and cumulative knowledge regarding health behaviors: are we moving in the right direction? Health Educ Res. 2005:20(3):275-90.

27. Andersson N, Mitchell S. Epidemiological geomatics in evaluation of mine risk education in Afghanistan: introducing population weighted raster maps. Int J Health Geogr. 2006;5:1.

28. Morzaria J, Šajna M. FuzzyTC, software package (in Python) for computing the fuzzy transitive closure of a fuzzy cognitive map. http://mysite.science. uottawa.ca/msajna//software/software.html. Accessed 2 May 2017.

29. Niesink P, Poulin K, Šajna M. Computing transitive closure of bipolar weighted digraphs. Discret Appl Math. 2013;161:217-43.

30. Giles B, Haas H, Šajna M, Findlay CS. Exploring aboriginal views of health using fuzzy cognitive maps and transitive closure. A case study of the determinants of diabetes. Canadian Journal of Public Health. 2008;99:411-7.

31. Acharya R, Kumar A, Bhat PS, Lim CM, lyengar SS, Kannathal N, et al. Classification of cardiac abnormalities using heart rate signals. Med Biol Eng Comput. 2004;42:288-93.

32. Young K, White P. Sport, physical danger, and injury: the experiences of elite women athletes. J Sport Soc Issues. 1995;19:45-61.

33. Pitt MM, Khandker SR, Cartwright J. Empowering women with micro finance: evidence from Bangladesh. Econ Dev Cult Chang. 2006;54:791-831.

34. Chimbiri AM. The condom is an "intruder" in marriage: evidence from rural Malawi. Soc Sci Med. 2007;64:1102-15.

\section{Submit your next manuscript to BioMed Central and we will help you at every step:}

- We accept pre-submission inquiries

- Our selector tool helps you to find the most relevant journal

- We provide round the clock customer support

- Convenient online submission

- Thorough peer review

- Inclusion in PubMed and all major indexing services

- Maximum visibility for your research

Submit your manuscript at www.biomedcentral.com/submit
Biomed Central 